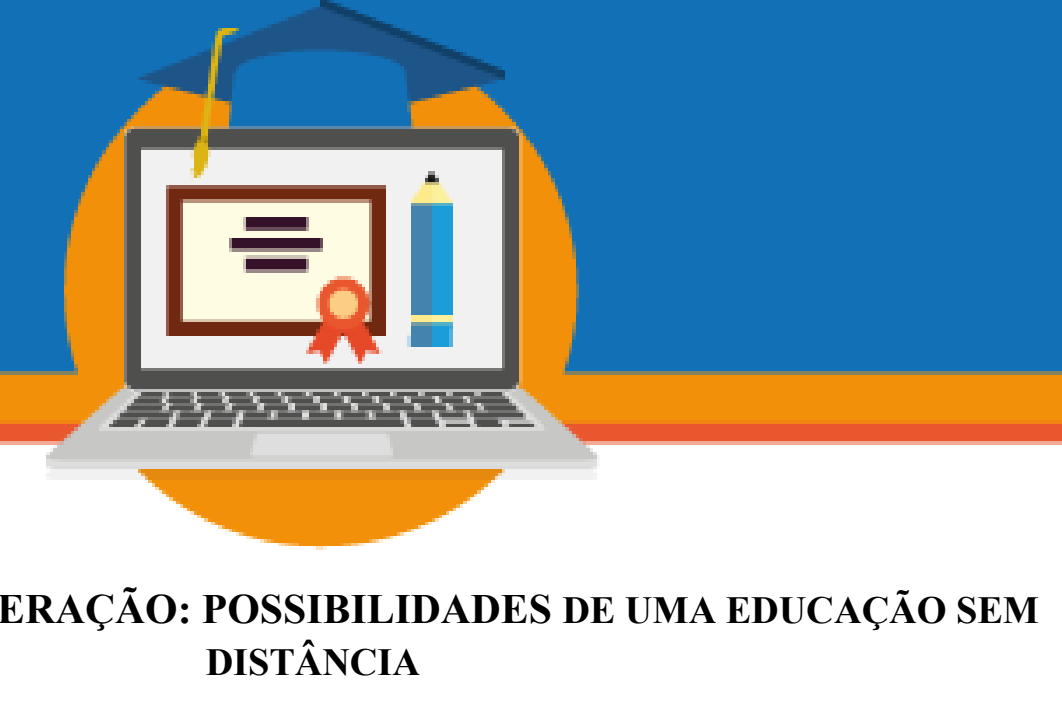

\title{
TECNOLOGIA E INTERAÇÃO: POSSIBILIDADES DE UMA EDUCAÇÃO SEM DISTÂNCIA
}

\author{
Blanca Martín Salvago ${ }^{1}$ \\ Universidade Católica Dom Bosco \\ Campo Grande - MS, Brasil \\ blanca@ucdb.br
}

\begin{abstract}
RESUMO
O presente artigo, baseado na Teoria da Distância Transacional, de Michael Moore, reflete a respeito do conceito de distância e suas implicações no processo de ensino e aprendizagem, seja presencial ou a distância. Distingue-se a distância física ou geográfica da distância psicológica. Assim como discute alguns aspectos relevantes que influenciam na sensação de distância de parte do aprendiz: a autonomia do aluno, o diálogo estabelecido entre os participantes de um curso e especificidades da comunicação na metodologia de Educação a Distância.
\end{abstract}

PALAVRAS-CHAVE: Teoria da Distância Transacional; Educação a Distância; Tecnologias Digitais de Informação e Comunicação.

\section{INTRODUÇÃO}

Nos últimos anos estamos assistindo a um aumento da oferta e demanda de cursos a distância. E, junto com o aumento no número de alunos, aumentam também os comentários, pesquisas e críticas que têm como alvo a metodologia de ensino a distância. Um dos maiores questionamentos é se distância e ensino são compatíveis. Pode se ensinar a distância sem desvirtuar a educação? Questionamentos deste tipo colocam na separação física e temporal dos participantes o principal critério para aceitar ou rejeitar uma metodologia de ensino.

\footnotetext{
${ }^{1}$ Acadêmica do Programa de Doutorado em Educação da Universidade Católica Dom Bosco. Linha II - Práticas Pedagógicas e suas Relações com a Formação Docente. Membro do Grupo de Estudos e Pesquisas de Tecnologia Educacional e Educação a Distância - GETED.
} 


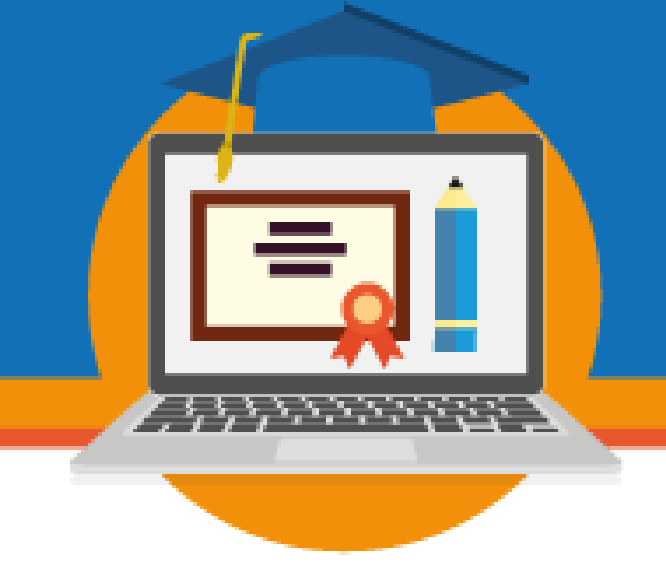

Nos itens a seguir abordamos, baseados na Teoria da Distância Transacional de Michael Moore, outra maneira de entender a distância, que pode ser minimizada por meio de uso de diferentes recursos tecnológicos. As Tecnologias Digitais de Informação e Comunicação podem ser de grande ajuda, se bem utilizadas, para a diminuição da sensação de distância, aproximando quem está fisicamente distante, potenciando as possibilidades de diálogo, interação, comunicação.

Dependendo qual é a proposta metodológica de cada curso, haverá diferentes níveis de interação entre os participantes (aluno-aluno; alunos-professor) e também do aluno com o conteúdo. Existem diferentes modelos educacionais que podem ser adotados em um curso a distância: em um extremo está o uso das ferramentas de informação e comunicação como meros instrumentos de entrega de conteúdos.

Mas essa não é a única realidade, no outro extremo, "está o suporte ao processo de construção de conhecimento por intermédio das facilidades de comunicação, denominado de 'estar junto virtual', que prevê um algo grau de interação entre professores e alunos, que estão em espaços diferentes, porém interagindo via internet" (VALENTE, 2011, p. 25).

\section{TEORIA DA DISTÂNCIA TRANSACIONAL}

O Decreto 5.622, de 19 de dezembro de 2005, que regulamenta o Art. 80 da Lei 9.394/96 (LDB), define a Educação a Distância, no seu Art. 1, como:

Art. 1 [...] modalidade educacional na qual a mediação didático-pedagógica nos processos de ensino e aprendizagem ocorre com a utilização de meios e tecnologias de informação e comunicação, com estudantes e professores desenvolvendo atividades educativas em lugares ou tempos diversos (BRASIL, 2005).

A definição destaca a distância espacial e temporal, que separa aluno e professor, como característica marcante da Educação a Distância - EAD. Mas, podemos nos perguntar com Maia e Mattar (2007, p. 15): “Afinal, o que significa a palavra ‘distância’ nessa expressão?” 
Existe uma separação no espaço, pois o aprendizado não fica restrito às paredes de uma instituição física de ensino, e uma separação temporal, pois mesmo que possa haver algumas atividades síncronas, em que professores e alunos precisam estar conectados ao mesmo tempo para a comunicação acontecer, a maioria das atividades é assíncrona, isto é, os participantes interagem em tempos diferenciados, havendo um lapso de tempo entre uma comunicação/pergunta e sua resposta. Se comparado à educação presencial, a distância faz com que a comunicação tenha características bem diferenciadas, como veremos no próximo item.

“Com a separação surge um espaço psicológico e comunicacional a ser transposto, um espaço de potenciais mal-entendidos entre as intervenções do instrutor e as do aluno. Este espaço psicológico e comunicacional é a distância transacional” (MOORE, 2002, p. 02). Mas, segundo o mesmo autor, essa distância transacional não é uma variável absoluta e sim relativa, pois varia em cada situação e para cada aluno. E acrescenta: “A grande questão a propósito da teoria da Educação a Distância é resumir as diferentes relações e a intensidade destas relações entre duas ou mais das variáveis que compõem a distância transacional, especialmente o comportamento de professores e alunos" (Ibidem, p.03).

Ou seja, segundo a teoria da distância transacional, o importante não é a distância física, geográfica, que há entre professores e alunos, “mas sim as relações pedagógicas e psicológicas que se estabelecem na relação de ensino. Portanto, independentemente da distância espacial ou temporal, os professores e os alunos podem estar mais ou menos distantes em $\mathrm{EaD}$, do ponto de vista transacional" (MAIA e MATTAR, 2007, p. 15). Segundo a mesma teoria, em qualquer processo de ensino e aprendizagem pode-se encontrar distância transacional, inclusive no ensino presencial.

Para Moore (2002), são três as variáveis que influenciam para que haja uma maior ou menor distância transacional. Essas variáveis são o diálogo educacional, ou seja, a interação entre alunos e professores; a estruturação dos programas educacionais e a autonomia do aluno. Em programas com menor distância transacional, os alunos recebem orientações por meio do diálogo com os professores, enquanto que em programas com distância transacional acentuada, “os diálogos são escassos ou inibidos, pois os materiais didáticos são estruturados para que 


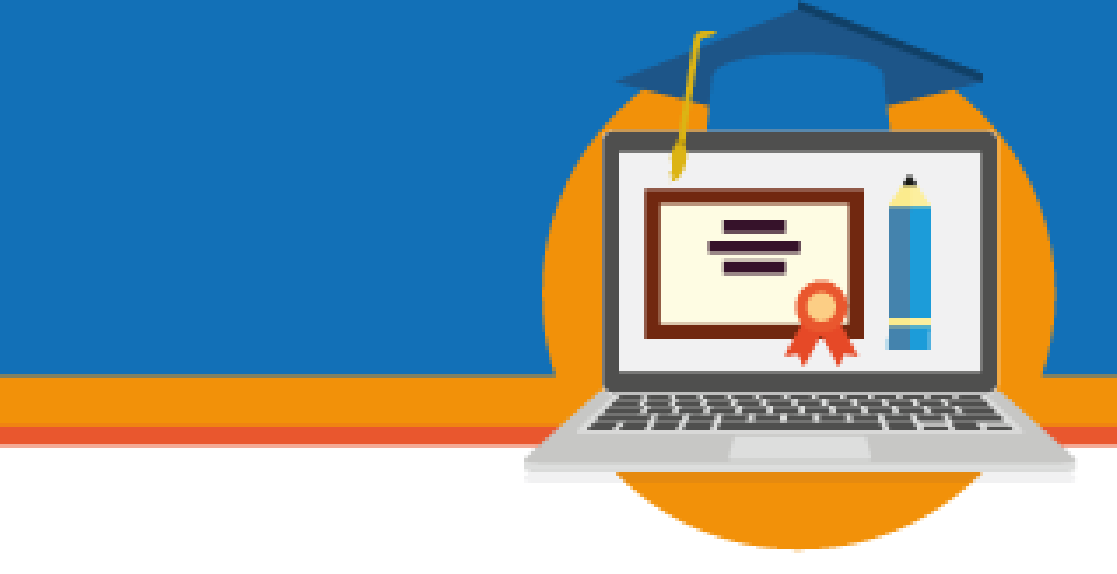

possam fornecer as orientações, as instruções e o aconselhamento [...]” (PELLI e ROSA, 2016, p. 29).

O sucesso do ensino a distância está imbricado com muitos fatores, uns dependem do programa de oferta da Instituição, outros estão mais relacionados à atitude que adotam alunos e professores:

O sucesso do ensino a distância depende da criação, por parte da instituição e do instrutor, de oportunidades adequadas para o diálogo entre professor e aluno, bem como de materiais didáticos adequadamente estruturados. Com frequência isto implicará tomar medidas para reduzir a distância transacional através do aumento do diálogo com o uso de teleconferência [...] É preciso muita habilidade para facilitar o grau de diálogo que seja suficiente e adequado para determinados alunos. Superar desta forma a distância transacional através da estruturação adequada da instrução e do uso adequado do diálogo é bastante trabalhoso. Requer o envolvimento de muitas habilidades diferentes e exige que estas habilidades sejam sistematicamente organizadas e aplicadas. Requer ainda mudanças no papel tradicional dos professores e fornece a base para a seleção dos meios para a instrução (MOORE, 2002, p. 6).

Portanto, segundo o autor, qualquer que seja a dinâmica de ensino-aprendizagem, um dos fatores mais importantes para a redução da distância transacional é que haja possibilidade de diálogo entre professor e alunos e a extensão em que o diálogo acontece, quer dizer, é importante tanto a quantidade quanto a qualidade dos diálogos. Essa perspectiva se baseia na teoria da aprendizagem de Vygotsky, "que explica a posição central da língua como um meio pelo qual o aluno constrói um modo de pensar. A relação com a autonomia do aluno é mostrada pela noção de transferência proposta por Vygotsky" (MOORE \& KEARSLEY, 2007, p. 242, grifos dos autores).

\subsection{Autonomia do aluno}

Wedemeyer propôs o conceito de aprendiz e aprendizagem independentes e utilizou o termo "estudo independente" para falar da Educação a Distância no Ensino Superior. Moore, influenciado pelo Wedemeyer, destacou a questão da autonomia do aluno como fundamental, percebendo que o aluno, que estuda a distância, comparativamente tem que ter um maior grau de responsabilidade na condução das atividades educacionais (VALENTE, 2011). 


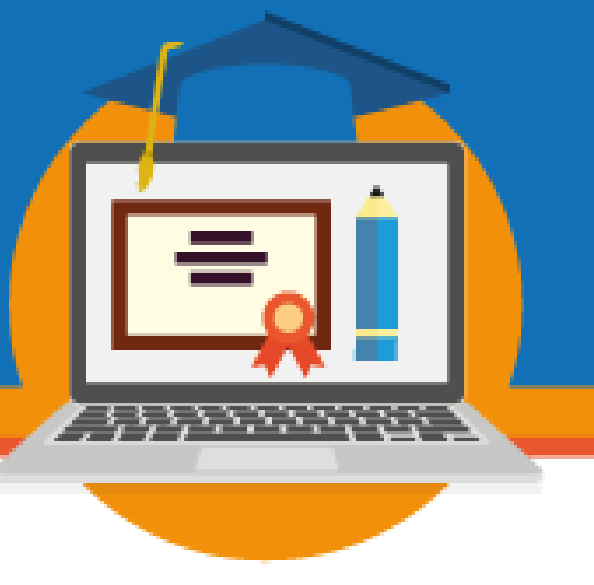

Mas o que deve se entender por autonomia? É preciso não confundir autonomia com autodidatismo. Autonomia não significa deixar o aluno isolado, abandonado à sua própria sorte, para ele se virar sozinho.

“Autonomia é algo muito mais complexo, faz parte [...] da construção do ser enquanto cidadão" (ROMÃO, 2008, p. 122). Há uma relação direta entre a autonomia que se requer no aluno e a estruturação do programa.

\begin{abstract}
Abordagens humanistas são mais dialógicas, menos estruturadas e conferem maior autonomia ao aluno, enquanto estratégias comportamentalistas baseiam-se em mecanismos de instrução programada, com o máximo de controle do processo de ensino-aprendizagem por parte do professor e, consequentemente, com pouca ou nenhuma autonomia oferecida ao aluno (TORI, 2017, p. 62)
\end{abstract}

A dificuldade vem pelo fato de que nem todos os alunos conseguem ser autônomos, nem têm a capacidade cognoscitiva nem emocional que se requerem para que seja possível falar de se autodirigir. "A liberdade constitui uma condição necessária, mas não suficiente para a autonomia. Ademais, a autonomia está mais para se revelar controlada e dependente do que independente e livre" (Ibidem). Isso significa que um bom exercício da autonomia não consiste em prescindir da relação e interação com os outros, aliás, é condição da autonomia a capacidade de relação e interação.

Segundo Morin (1995 apud MORAES, 2000, p. 07):

[...] esta autonomia é sempre relativa, pois é a expressão de sua capacidade de relacionar-se com o que lhe está ao seu redor, de sua capacidade de auto-organizar-se em relação ao seu entorno. Para sermos autônomos necessitamos interagir com o mundo exterior, o que para o paradigma tradicional era impossível já que sujeito e objeto estavam separados.

Quando a pessoa percebe que não tem autonomia, isso pode causar perda da autoestima e desmotivação para a realização das atividades educacionais. Mas ter autonomia não basta, as pessoas precisam se relacionar, precisam sentir que há quem se preocupe com elas (TORI, 2017, p. 88), Por outro lado, o aluno não pode cair na autossuficiência: "Ter a consciência de que ninguém se basta a si mesmo é um bom começo. Este parece ser um requisito fundamental para começar a exercer a autonomia" (ROMÃO, 2008, pp. 124-125).

\title{
II SEMINÁRIO DE EDUCAÇÃO A DISTÂNCIA
}

EaD na região Centro-Oeste: Institucionalização, Limites e Potencialidades

12 a 14 de abril de 2018 - Campo Grande/MS 


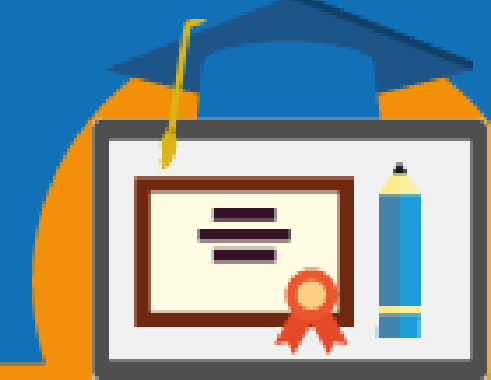

\section{EDUCAÇÃO A DISTÂNCIA X EDUCAÇÃO PRESENCIAL?}

“A aproximação (do aluno com o conteúdo, do aluno com o professor ou do aluno com os colegas de aprendizagem) é condição necessária, mas não suficiente, para que ocorra aprendizagem" (TORI, 2017, p. 32). Sendo assim, a educação a distância seria um paradoxo. E parece que o caminho mais simples e óbvio de superar essa barreira seria colocar todos os participantes em um mesmo espaço físico, mas não é a única possibilidade. "Os meios de comunicação e as tecnologias interativas, dos correios à telepresença também podem aproximar, com menos custo e maior eficiência" (Ibidem).

Já vimos no item anterior que, segundo a teoria da distância transacional, a distância é algo relativo e não exclusivo da modalidade a distância, estando também presente na educação presencial. Portanto cabe se perguntar se devemos distinguir as duas modalidades enfatizando a distância (educação a distância) ou a presença física (educação presencial).

Não se faz educação sem se estabelecer relação entre as pessoas, sem encontros e interações, no entanto, há muitas maneiras de se fazer presente e de estabelecer relações:

Há, no entanto, encontros e encontros, distâncias e distâncias. Educação com distância parece possível e é até positiva. Distância [...] para respirar, para refletir, para silenciar e escutar os ruídos do silêncio educativo. Educação com isolamento, ausência de vínculos, sem que o encontro seja transformado em relação, não é educação. Por isso, insistimos, é necessário identificar de que encontro, de que distância estamos falando (ROMÃO, 2008, p. 101).

Tori (2017, p. 31) destaca que "a separação da educação em duas modalidades não necessariamente contribui para o seu avanço". As evidentes diferenças em termos de requisitos, forma, métodos de aprendizagem, etc., não justificaria essa distinção, do mesmo jeito que não se fala de modalidade de educação laborativa para as atividades desenvolvidas em um laboratório.

O autor coloca um exemplo esclarecedor para ilustrar sua teoria: um famoso cientista, ganhador de Premio Nobel, ministrando uma palestra em um estádio de futebol, na presença de 
milhares de alunos universitários. Tecnicamente essa situação seria considerada uma atividade presencial, pois todos estão reunidos em um mesmo lugar (estádio de futebol) e estão assistindo a uma atividade síncrona (a palestra do cientista afamado). Imaginemos outra situação: três alunos da mesma universidade irão "participar de uma videoconferência interativa com aquele mesmo cientista, para discutirem e esclarecerem suas dúvidas a respeito de determinado tema apresentado" (TORI, 2017, p. 60). Tecnicamente esta última atividade, devido ao uso da videoconferência para a comunicação entre os participantes, seria considerada atividade a distância.

Nesses dois exemplos, fica claro que a distinção das modalidades atendendo à distância ou presença física, para termos uma noção da distância transacional, é muito relativa. Imaginase que no primeiro caso, mesmo estando todos presentes do ponto de vista físico, a sensação de proximidade e interação seria mínima; enquanto que no segundo caso, mesmo sem estarem presentes fisicamente, a sensação de proximidade é muito maior, assim como a possibilidade de interação. É evidente, então, que uma atividade mediada por um recurso tecnológico e sem contar com a presença física nem sempre será necessariamente uma atividade com sensação de distância. Portanto, podemos concluir, com o autor, que não é adequada a contraposição das duas modalidades e, portanto, também não seria adequado fazer referência aos dois métodos de ensino fazendo referência apenas à distância física e temporal existente ou não entre seus membros.

Por outro lado, é importante salientar que as tecnologias de redução de distâncias já estão incorporadas ao nosso cotidiano e já usufruímos de suas vantagens em outros contextos, que não o educacional. Por exemplo, as redes sociais que podem aproximar pessoas separadas por milhares de quilômetros utilizando meios de comunicação síncronos.

Com a ajuda das tecnologias interativas, consegue-se aumentar a sensação de presença. Para a aprendizagem, qualidade é mais importante que quantidade, portanto bastaria planejar bem alguns encontros ao vivo para aumentar a sociabilidade e diminuir a evasão devida à sensação de solidão (distância transacional) (TORI, 2017). 


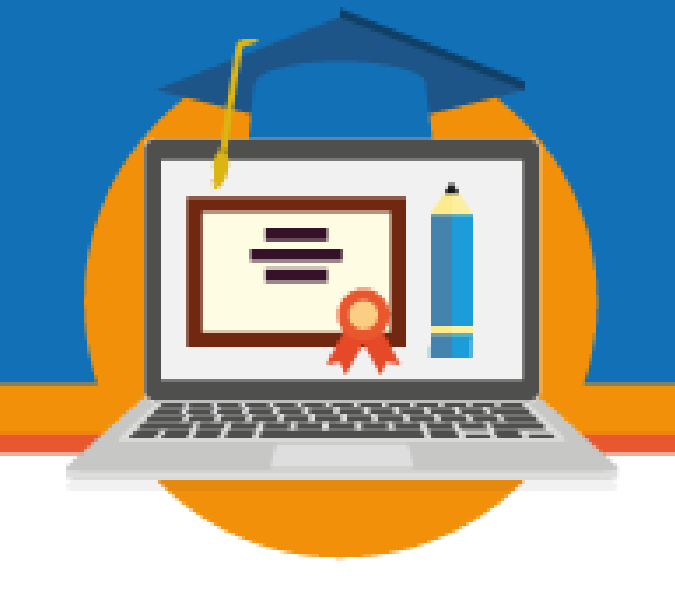

O conceito de presença fica alargado com as tecnologias interativas. Por meio de novas linguagens, é possível "estarmos presentes" mesmo estando a distância. Biocca (1997, apud TORI, 2017, p. 95) distingue três tipos de presença: presença física (imersão em um ambiente físico ou sensação de presença física), presença social (sensação de estar com alguém e autopresença (sensação de autoconsciência). A presença social é a mais importante para a motivação do aluno, pois tão importante como a interação com o professor é a interação com os outros colegas.

Não se trata, pois, de suprimir a distância, mas precisamos aprender a conviver com ela, para que nela seja possível uma presença dialogada: "É preciso, pois, não querer a tudo custo suspender a distância, mas aprender a lidar com ela, de modo que seja possível fazer nascer dela mesma a presença” (ROMÃO, 2008, p. 87).

Resumindo, tanto a distância quanto a presença são relativas e dependem de múltiplos fatores, entre outros as tecnologias que são usadas como mediação para a interação dos participantes.

No próximo item abordaremos a potencialidade das tecnologias interativas no processo de construção do conhecimento. Elas favorecem? Atrapalham?

\section{AS TECNOLOGIAS INTERATIVAS NA EDUCAÇÃO}

“As novas tecnologias digitais vêm favorecendo novas formas de acesso à informação, novos estilos de pensar, raciocinar e novas dinâmicas no processo de construção de conhecimento" (MORAES, 2000, p. 01). Mas isso não quer dizer que apenas o uso de tais tecnologias seja garantia de qualquer mudança, muito menos de mudança no sentido de avanço ou conquista de maior qualidade de ensino.

Não se pode cair em um determinismo tecnológico, como se o uso de uma tecnologia necessariamente fosse determinante do processo em que são utilizadas, mas também não 


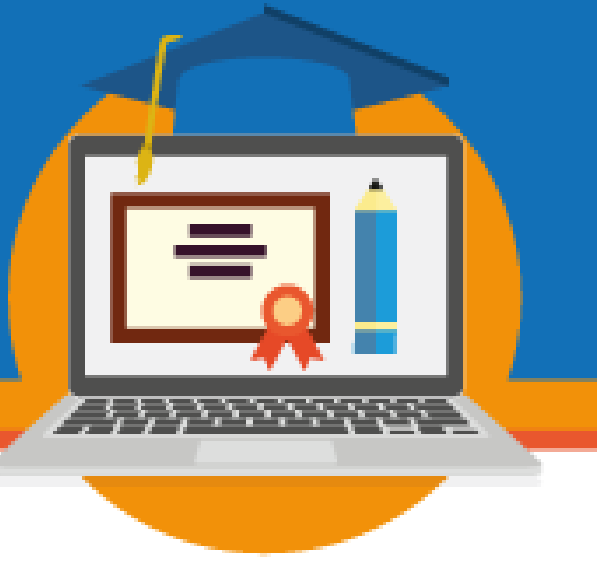

podemos pensar que sejam neutras, podendo ser utilizadas independente de qual seja a atividade ou os objetivos que se pretendem com elas (BARRETO, 2003, p. 273).

Se bem é verdade, como destaca Barreto (2003, p. 275) que "a presença das TIC, a despeito da sua importância, não constitui condição suficiente para o encaminhamento das múltiplas questões educacionais, sejam elas novas ou velhas" (grifo nosso), Moraes destaca que pesquisas realizadas em universidades brasileiras (UFRGS, UNICAMP, PUC/SP) "sinalizam que as novas tecnologias digitais podem se constituir em ferramentas importantes para o desenvolvimento de processos construtivos de aprendizagem, para a criação de novos espaços de aprendizagem" (grifo nosso) (MORAES, 2000, p. 02).

As TIC, além de servirem como fonte de informações e como meio educacional, têm outras potencialidades:

[...] podem servir para o desenvolvimento de atividades que facilitem o desenvolvimento da autonomia, da solidariedade, da criatividade, da cooperação e da parceria, como ferramentas que permitem a criação de ambientes virtuais, onde também é possível vivenciar valores humanos superiores associados aos processos de construção de conhecimento (MORAES, 2000, p. 04).

Colaborando para o desenvolvimento de novas formas de pensar, estas ferramentas supõem muito mais do que apenas subsídios educacionais, "podendo se constituir em instrumentos valiosos para um reposicionamento mais adequado do indivíduo diante do mundo e da vida" (Ibidem). Não podemos considerar a aprendizagem e a vida como realidades separadas, uma influência na outra. Portanto, podemos dizer que essas tecnologias são instrumentos valiosos para a vida dos indivíduos e suas relações em sociedade.

É bom aqui lembrar o conceito de educação que, de acordo com sua etimologia-educare - "remete-nos ao trabalho de criar, de alimentar, ou educare que implica conduzir para fora, em ação, cujo movimento se constitui de mão dupla, ou seja, em relação, com o outro, em comunhão com o mundo, do que já nos alertou Paulo Freire” (grifos do autor) (ROMÃO, 2008, p. 19).

Mas é lógico que tudo isso não acontece de maneira automática pelo simples acesso e uso das tecnologias. O decisivo é saber utilizá-las de maneira a estimular o pensamento crítico 


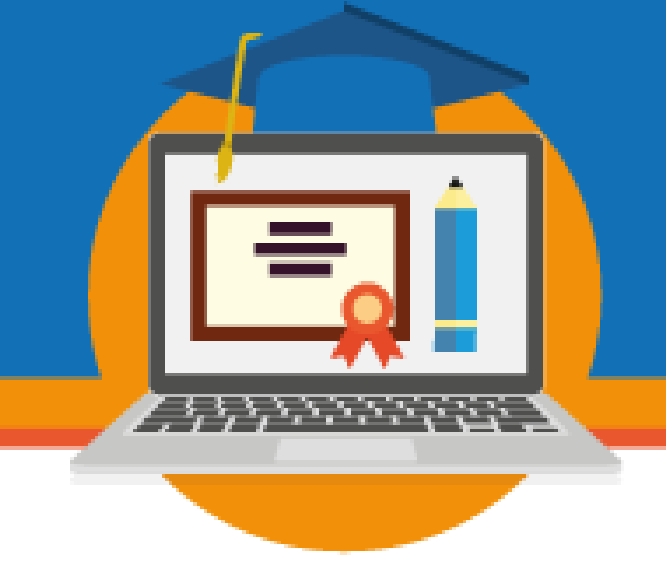

e reflexivo, a criatividade, a interatividade. "[...] Necessitamos de um modelo educacional que colabore para o resgate da inteireza humana, para o desenvolvimento da intuição, da imaginação e a compreensão do papel da emoção em seu constante diálogo com a razão" (MORAES, 2000, p. 05).

\section{COMUNICAÇÃO NA EDUCAÇÃO A DISTÂNCIA}

As interfaces disponíveis no ambiente virtual de aprendizagem devem favorecer a interatividade, o diálogo entre os participantes de maneira a favorecer o diálogo bidirecional, diminuindo a distância transacional e colaborando para a aprendizagem colaborativa. "A modalidade comunicacional que emerge com a cibercultura chama-se interatividade [...] $\mathrm{O}$ termo significa a comunicação que se faz entre emissão e recepção entendida como co-criação da mensagem" (SILVA, 2004, p. 4).

A comunicação na EAD é na sua maioria assíncrona e escrita. Isso faz com que a comunicação seja mais difícil, pois os envolvidos não têm a contribuição dos gestos faciais, a postura e o tom de voz como aliados para a compreensão da mensagem e das emoções do interlocutor. Isso contribui com que não raramente haja mal entendidos ou erros na comunicação. O que foi escrito com uma intenção pode ser entendido de maneira diferente ou até contrária, levando a possíveis tensões e conflitos.

A maior vantagem da comunicação escrita é que fica registro de todas as trocas e orientações, assim como a data e hora de cada comunicação. Isso permite a professor e aluno o resgate fácil do histórico das comunicações. A desvantagem, como sinalizado, é a limitação da linguagem escrita quanto à entonação da comunicação, emoções, sentimentos, etc.

Conforme Moore e Kearsley (2007, p. 129), as pessoas são mais cautelosas no contexto da comunicação virtual, e isso acontece de maneira especial na comunicação assíncrona. "Por essa razão, seja qual for a tecnologia de comunicação usada, a participação poderá não ocorrer, a não ser que seja bem planejada e os instrutores tenham treinamento para facilitá-la”. 


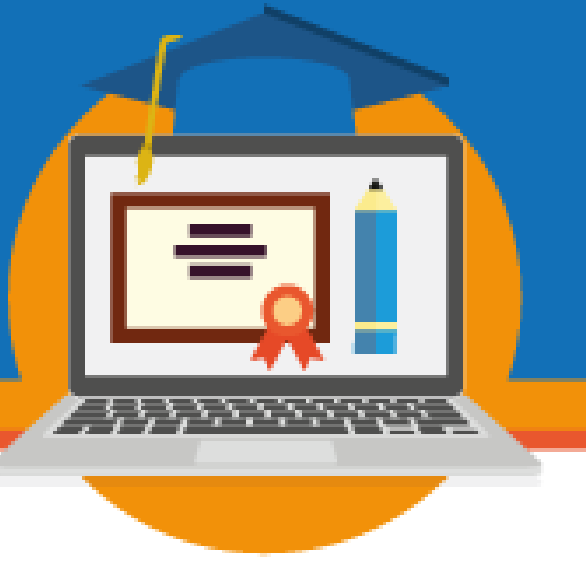

Segundo Leffa (2001 apud RIBEIRO, 2012, p. 794), a linguagem escrita no contexto da internet, pode parecer fria e sem sentimento, mas "pode [...] tornar-se extremamente carregada de sentimentos e emoções. É preciso considerar que essa linguagem escrita pode sim dar conta da transmissão de sentimentos e emoções".

No contexto do ciberespaço, os usuários da Internet encontraram nos emoticons a alternativa de que precisavam para estabelecer de forma eficiente o processo comunicativo, a despeito dos obstáculos que pudessem surgir em situações em que os participantes não dominassem os mesmos códigos de linguagem (SERRA, 2005, p. 43).

Com a utilização desses recursos, a comunicação consegue se aproximar mais das características face a face, pois é possível expressar estados emocionais que não transparecem facilmente na linguagem escrita. De qualquer maneira, seja se utilizando de recursos de imagem ou não, o importante é que o professor consiga humanizar a relação com o aluno, sem cair no formalismo da comunicação meramente técnica e levando em conta que o aluno é um ser humano que precisa de proximidade e de atenção para criar um clima de confiança e de diálogo aberto.

Novos contextos supõem novos desafios: outras maneiras de se comunicar, diferentes estratégias de motivação, novas interfaces de comunicação, adaptação às particularidades da comunicação escrita, etc. As relações são virtuais, mas as emoções das pessoas que se envolvem na relação são reais.

\section{CONSIDERAÇÕES FINAIS}

Diante da explanação feita, pode se concluir a relatividade da distância, se considerada nos termos da Teoria da Distância Transacional. Portanto, não se justifica colocar como critério de aceitação ou rejeição de um curso apenas pelo fato de contar ou não com a presença física dos participantes. Também não se justifica colocar a distância espacial e temporal como principal característica da metodologia da chamada Educação a Distância. 


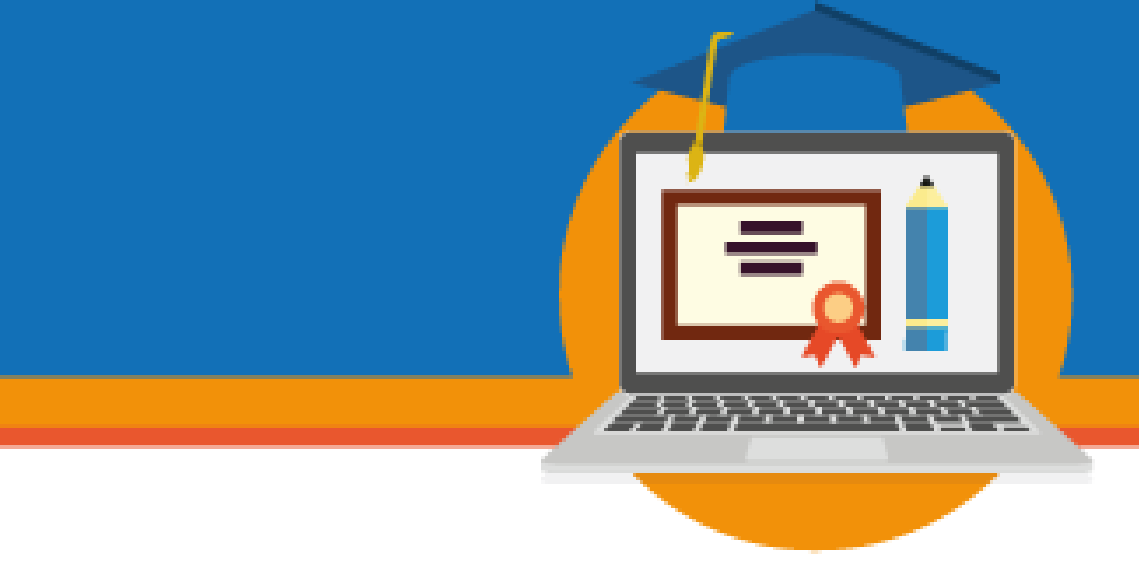

A sensação de distância independe da distância geográfica que separa as pessoas. Para que a separação física entre aluno-aluno e entre aluno-professor não seja um entrave, o modelo educacional adotado deve contar com meios que propiciem o diálogo e possibilitem a aproximação, mesmo que esta seja virtual.

O uso de uma tecnologia ou outra não garante necessariamente que a interação venha a acontecer, não garante um ganho em termos de qualidade, mas existem ferramentas tecnológicas que podem ser utilizadas como aliadas para diminuir a sensação de distância, levando o aluno a um "estar junto virtual", construindo o conhecimento de maneira mais colaborativa, interagindo por meio da internet.

\section{REFERÊNCIAS}

ALMEIDA, Maria Elizabeth Bianconcini de. Incorporação da Tecnologia de Informação na Escola: vencendo desafios, articulando saberes, tecendo a rede. 2002. Disponível em: $<$ http://www.nied.unicamp.br/oea/pub/livro3/index.html>. Acesso em: 10 fev. 2018.

BARRETO, Raquel Goulart. Tecnologias na Formação de Professores: o discurso do MEC. Educação e Pesquisa, São Paulo, v.29, n.2, p. 271-286, jul./dez. 2003.

BRASIL. Decreto 5.622, de 19 de dezembro de 2005. Regulamenta o art. 80 da Lei no 9.394, de 20 de dezembro de 1996, que estabelece as diretrizes e bases da educação nacional. Disponível em: $\quad<$ http://www.planalto.gov.br/ccivil 03/_Ato20042006/2005/Decreto/D5622.htm>. Acesso em:10 fev. 2018.

MAIA, Carmem; MATTAR, João. ABC da EaD. São Paulo: Pearson Prentice Hall, 2007.

MOORE, Michael G. Teoria da Distância Transacional. 2002. Disponível em: $<$ http://www.abed.org.br/revistacientifica/Revista_PDF_Doc/2002 Teoria_Distancia_Transac ional Michael Moore.pdf>. Acesso em: 10 fev. 2018.

MOORE, Michael G.; KEARSLEY, Greg, Educação a Distância: Uma visão integrada. São Paulo: Cengage Learning, 2007. 


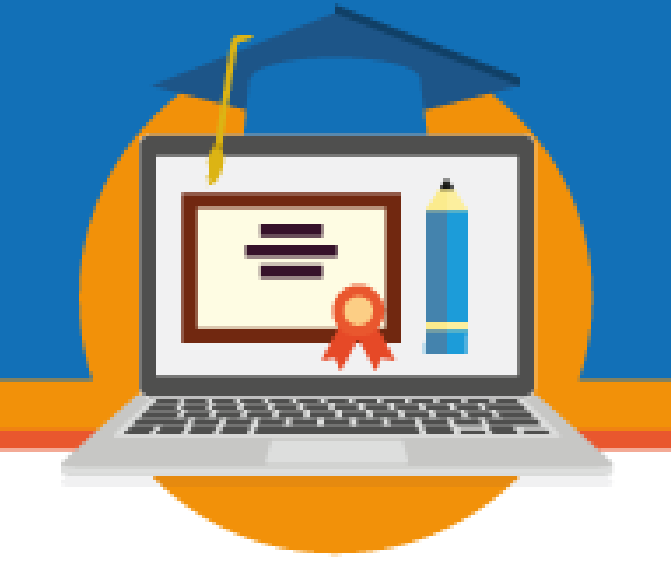

MORAES, Maria Cândida. Tecendo a Rede, mas com que Paradigma? 2000. Disponível em: $<$ http://www.nied.unicamp.br/oea/pub/livro3/>. Acesso em: 10 fev. 2018.

PELLI, Débora; ROSA, Milton. Minimizando a Distância Transacional: aplicando Teorias da Educação a Distância para mediar a aprendizagem de conteúdos da Geometria Plana com a utilização do software GeoGebra na Plataforma Moodle. In: MACIEL, Cristiano; ALONSO, Kátia Morosov; PANIAGO, Maria Cristina. (Org.) A Educação a Distância: interação entre sujeitos, plataformas e recursos. Cuiabá: EdUFMT, 2016.

RIBEIRO, Simone Regina de Oliveira. Linguagem e Afetividade em EAD: Questões interdisciplinares. Cadernos do Congresso Nacional de Linguística e Fonologia, Vol. XVI, No 04 Anais do XVI CNLF, 2012.

ROMÃO, Eliana. A relação educativa: por meio de falas, fios e cartas. Maceió: EDUFAL, 2008.

SERRA, Daniela Tereza Santos. Afetividade, aprendizagem e Educação Online. Dissertação de Mestrado, Educação, Ciência e Tecnologia, Universidade Católica de Minas Gerais, Belo Horizonte, 2005.

SILVA, Fabiane Muniz da; CARVALHO, Vilson Sérgio de. O papel das Relações Afetivas na Educação a Distância no Ensino Superior. 2014. Disponível em: $<$ http://www.abed.org.br/hotsite/20-ciaed/pt/anais/pdf/28.pdf $>$. Acesso em: 10 fev. 2018.

TORI, Romero. Educação sem distância. As tecnologias interativas na redução de distâncias em ensino e aprendizagem. 2. ed. São Paulo: Artesanato Educacional, 2017.

VALENTE, José Armando. Educação a Distância: criando abordagens educacionais que possibilitam a construção de conhecimento. In: ARANTES, Valéria Amorim (Org.).

Educação a Distância: pontos e contrapontos. São Paulo: Summus, 2011. 